\title{
Phenolic Constituents of Galla Rhois with Hepatoprotective Effects on Tacrine- and Nitrofurantoin-Induced Cytotoxicity in Hep G2 Cells
}

\author{
Ren-Bo AN, ${ }^{a, b}$ Hyuncheol $\mathrm{OH}^{c}{ }^{c}$ and Youn-Chul $\mathrm{KIM}^{*, a}$ \\ ${ }^{a}$ College of Pharmacy, Wonkwang University; Iksan 570-749, Korea: ${ }^{b}$ College of Pharmacy, Yanbian University; Yanji, \\ Jilin 133000, China: and ${ }^{c}$ MCBI \& College of Natural Sciences, Silla University; Busan 617-736, Korea. \\ Received April 18, 2005; accepted August 2, 2005
}

\begin{abstract}
The bioassay-guided fractionation of the MeOH extract of Galla Rhois furnished two hepatoprotective compounds, an equilibrium mixture of 3-galloyl-gallic acid and 4-galloyl-gallic acid isomers (3), 1,2,3,4,6-penta- $O$ galloyl- $\beta$-D-glucose (4), and two inactive phenolic compounds, gallic acid methyl ester (1) and gallic acid (2). Compounds 3 and 4 showed significant hepatoprotective effects with $\mathrm{EC}_{50}$ values of $70.39 \pm 5.4$ and $29.51 \pm 0.7 \mu \mathrm{M}$, respectively, against tacrine-induced cytotoxicity, and $150.9 \pm 6.4$ and $23.81 \pm 0.5 \mu \mathrm{M}$, respectively, against nitrofurantoin-induced cytotoxicity in Hep $\mathbf{G 2}$ cells.
\end{abstract}

Key words Galla Rhois; hepatoprotective; drug-induced cytotoxicity; Hep G2 cell

When searching for hepatoprotective agents from natural sources, it is important that relevant models of human liver toxicosis are used in order to identify agents with therapeutic potential. Thus, we considered the use of hepatotoxic agents relevant to human liver toxicosis in assay protocols. Examples of such hepatotoxic agents include pharmaceutical agents like tacrine and nitrofurantoin. Tacrine $(1,2,3,4$ tetrahydro-9-aminoacridine hydrochloride) is an acetylcholinesterase inhibitor that is approved for the treatment of Alzheimer's disease. However, tacrine treatment for Alzheimer's disease results in reversible hepatotoxicity in $30-50 \%$ of patients, which seriously limits its clinical use. ${ }^{1)}$ Nitrofurantoin \{1-(5-nitro-2-furfurylideneamino)-hydantoin is a synthetic nitrofuran that is commonly used for the treatment and prophylaxis of urinary tract infections, but its use is associated with liver cirrhosis and fatal liver necrosis. ${ }^{2)}$ Therefore, the identification of constituents in natural products that have preventive effects on tacrine- or nitrofurantoininduced hepatotoxicity would be valuable. In the present study, an immortalized human hepatoma cell line, Hep G2 was employed to screen for agents that protect against tacrine- or nitrofurantoin-induced hepatotoxicity. This cellline was chosen because it retains many cellular functions often lost by primary hepatocytes, e.g., the expression of hepatocyte-specific cell surface receptors and the synthesis and secretion of plasma proteins. ${ }^{3)}$ During the course of our continuing screening studies ${ }^{4-8)}$ for natural hepatoprotective agents, we found that the EtOAc soluble fraction of the $\mathrm{MeOH}$ extract of Galla Rhois, a traditional Chinese medicine to treat diarrhea and bleeding, ${ }^{9)}$ showed promising hepatoprotective activity. We describe the isolation and identification of the hepatoprotective constituents of Galla Rhois.

\section{MATERIALS AND METHODS}

Materials RPMI 1640 medium, trypsin-ethylene-diaminetetraacetic acid (EDTA), and antibiotics were purchased from Gibco Laboratories (Grand Island, NY, U.S.A.). Fetal bovine serum (FBS) was obtained from Hyclone Laboratories (Logan, UT, U.S.A.). Tacrine, nitrofurantoin, silybin, (-)-epigallocatechin gallate, and 3'-(4,5-dimethylthiazol-2yl)-2,5-diphenyltetrazolium bromide (MTT) were purchased from Sigma Chemical Co. (St. Louis, MO, U.S.A.). Ninetysix well tissue culture plates and other tissue culture dishes were purchased from Nunc Inc. (North Aurora, IL, U.S.A.).

Instruments NMR spectra were recorded in $\mathrm{MeOH}-d_{4}$ using a JEOL Eclipse- $500 \mathrm{MHz}$ spectrometer $(500 \mathrm{MHz}$ for ${ }^{1} \mathrm{H}, 125 \mathrm{MHz}$ for ${ }^{13} \mathrm{C}$ ), and chemical shifts are quoted versus tetramethylsilane. ESI-MS spectra were measured on a Quattro LC-MS (Micromass), and medium-pressure liquid chromatography (MPLC) was performed using a Yamazen Pump 540 (Yamazen, Japan).

Extraction and Isolation Galla Rhois was purchased from the University Oriental Drugstore, Iksan, Korea in October 2004. A voucher specimen (No. WP04-296) was deposited at the Herbarium of the College of Pharmacy, Wonkwang University (Korea).

Dried and pulverized Galla Rhois $(1 \mathrm{~kg})$ was extracted twice with $\mathrm{MeOH}(21)$ at room temperature for $2 \mathrm{~d}$. The $\mathrm{MeOH}$ extract (340 g) was dissolved in $60 \%$ aqueous $\mathrm{MeOH}$ and partitioned with $n$-hexane $(2 \times 11)$, followed by $\mathrm{CH}_{2} \mathrm{Cl}_{2}$ $(2 \times 11)$. The $60 \%$ aqueous $\mathrm{MeOH}$ layer was then evaporated in vacuo, and the resulting residue was dissolved in $\mathrm{H}_{2} \mathrm{O}$ and successively partitioned with EtOAc $(2 \times 11)$ and $n-\mathrm{BuOH}$ $(2 \times 11)$. A portion $(24 \mathrm{~g})$ of the bioactive EtOAc soluble extract $(280 \mathrm{~g})$ was then fractionated by vacuum liquid chromatography (VLC) using $\mathrm{CH}_{2} \mathrm{Cl}_{2}$ and mixtures of $\mathrm{CH}_{2} \mathrm{Cl}_{2}-$ $\mathrm{MeOH}$ to afford four fractions (Fr. A-D). Fr. A (780 mg) was subjected to column chromatography on silica gel and eluted with a stepwise gradient of $\mathrm{CH}_{2} \mathrm{Cl}_{2}-\mathrm{MeOH}$ (20: $1 \rightarrow 9: 1$ ) to give gallic acid methyl ester (compound 1, 145 $\mathrm{mg}$, pale yellow amorphous powder). Fr. B (2.6 g) was chromatographed on a silica gel column with $\mathrm{CH}_{2} \mathrm{Cl}_{2}-\mathrm{MeOH}$ $(9: 1)$ to yield gallic acid (compound $2,170 \mathrm{mg}$, pale yellow amorphous powder). Fr. C (1.1 g) was also chromatographed on a silica gel column using $\mathrm{CH}_{2} \mathrm{Cl}_{2}-\mathrm{MeOH}(4: 1)$ to furnish two subfractions (Fr. C1, 2). Fr. C2 (320 mg) was chromatographed on a Sephadex LH-20 column (eluent: $\mathrm{MeOH}$ ) to yield an equilibrium mixture of 3-galloyl-gallic acid and 4-galloyl-gallic acid isomers (compound 3, $114 \mathrm{mg}$, pale yellow amorphous powder). Fr. D (1 g) was chromatographed on a silica gel column using $\mathrm{CH}_{2} \mathrm{Cl}_{2}-\mathrm{MeOH}-\mathrm{H}_{2} \mathrm{O}(8: 2: 0.2)$ to afford three subfractions (Fr. D1-3). Fr. D3 (6.2 g) was subjected to reversed-phase MPLC (column: ODS-S-50 B, 
$120 \AA, 50 \mu \mathrm{m})$ and eluted with $35 \% \mathrm{MeOH}$ in $\mathrm{H}_{2} \mathrm{O}$ to give $1,2,3,4,6$-penta- $O$-galloyl- $\beta$-D-glucopyranose (compound $\mathbf{4}$, $170 \mathrm{mg}$, a pale yellow amorphous powder). Compounds $\mathbf{1}-\mathbf{4}$ were identified as gallic acid methyl ester, ${ }^{10)}$ gallic acid ${ }^{11)}$ an equilibrium mixture of 3-galloyl-gallic acid and 4-galloylgallic acid isomers, ${ }^{12)}$ and $1,2,3,4,6$-penta- $O$-galloyl- $\beta$-D-glucopyranose, ${ }^{13)}$ respectively, by comparing MS, ${ }^{1} \mathrm{H}-\mathrm{NMR}$, and ${ }^{13} \mathrm{C}-\mathrm{NMR}$ data with literature values. Full details of the isolation and characterization are available on request.

In Vitro Assay of the Hepatoprotective Activity on Drug-Induced Cytotoxicity in Hep G2 Cells Drug-induced cytotoxicity assays were conducted using a minor modification of the method described by Song et al. ${ }^{5)}$ Briefly, human hepatoma Hep G2 cells from the American Type Culture Collection were maintained at $2 \times 10^{5}$ cells/well in complete medium consisting of RPMI supplemented with $10 \%$ heat-inactivated FBS, penicillin $\mathrm{G}(100 \mathrm{IU} / \mathrm{ml})$, and streptomycin $(100 \mu \mathrm{g} / \mathrm{ml})$, and then incubated at $37^{\circ} \mathrm{C}$ in a humidified atmosphere containing $5 \% \mathrm{CO}_{2}$ and $95 \%$ air. Cytotoxicity was assessed by MTT assay by incubating cells for $2 \mathrm{~h}$ in the corresponding medium in the presence of $1.2 \mathrm{~mm}$ tacrine or $1.7 \mathrm{~mm}$ nitrofurantoin. These concentrations were found to produce cell viabilities of $50 \%$ in prior dose-response study or in the absence of these drugs. Samples were tested at five or six different concentrations $(10,30,50,75,100,200 \mu \mathrm{M}$ for compound $3,3,10,30,50,75 \mu \mathrm{M}$ for compound 4) in triplicate. $\mathrm{EC}_{50}$ values for hepatoprotective effects (defined as percentage viability versus the respective control) were calculated by linear regression using mean values, and are expressed as means \pm S.D. of three independent experiments. Results were compared using one-way ANOVA and Tukey's multiple comparison test. Statistically significant differences between groups were defined as having $p$ values of $<0.05$. Calculations were performed using GraphPad Prism program (GraphPad Software, Inc., San Diego, CA, U.S.A.).

\section{RESULTS AND DISCUSSION}

In the present study, we investigated the $\mathrm{MeOH}$ extract of Galla Rhois with the aim of identifying natural hepatoprotective compounds. Of the $\mathrm{MeOH}$ extract fractions obtained during the course of the study, the EtOAc-soluble fraction was found to have a marked protective effect on Hep G2 cells treated with tacrine at $200 \mu \mathrm{g} / \mathrm{ml}$. The subsequent bioassayguided fractionation of this EtOAc-soluble fraction led to the isolation of four compounds, i.e., gallic acid methyl ester (compound 1), gallic acid (compound 2), an equilibrium mixture of 3-galloyl-gallic acid and 4-galloyl-gallic acid isomers (compound 3), and 1,2,3,4,6-penta- $O$-galloyl- $\beta$-D-glucopyranose (compound 4) (Chart 1). And, of these compounds, 3 and $\mathbf{4}$ were found to have marked protective effects on tacrine-induced cytotoxicity in human liver-derived Hep $\mathrm{G} 2$ cells with $\mathrm{EC}_{50}$ values of $70.39 \pm 5.4$ and $29.51 \pm 0.7 \mu \mathrm{M}$, respectively (Figs. 1A, B). MTT assays were used as an indirect measure of cell viability. Moreover, compounds 3 and 4 showed no cytotoxicity at concentrations of $<200 \mu \mathrm{M}$ for compound 3 and $<75 \mu \mathrm{M}$ for compound 4 (data not shown). Silybin, one of the most well-known hepatoprotective agents was used as a positive control, and had an $\mathrm{EC}_{50}$ value of $86.26 \pm 0.5 \mu \mathrm{M}$. Although the mechanism underlying the hepatotoxicity of tacrine remains to be elucidated, it has been
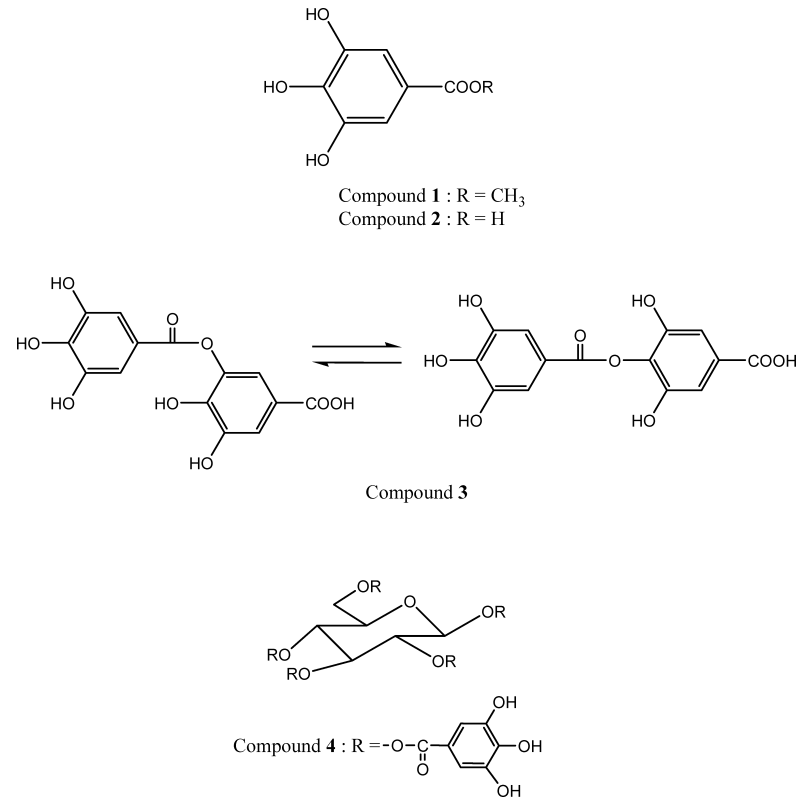

Chart 1. The Structures of Compounds 1-4 Isolated from Galla Rhois

shown that tacrine alters intracellular glutathione concentrations in cultured hepatocytes, which suggests that its toxic effect involve reactive oxygen species and lipid peroxidation, ${ }^{14}$ ) and that antioxidative compounds may protect against tacrine-induced hepatotoxicity. Therefore, we surmise that the observed hepatoprotective effects of compounds $\mathbf{3}$ and $\mathbf{4}$ are related to their antioxidative activities, since these compounds are plant-derived polyphenols, which are known to have antioxidative effects.

In conjunction with the hepatoprotective effects of compounds $\mathbf{3}$ and $\mathbf{4}$ on tacrine-induced cytotoxicity, we also assessed their protective effects on nitrofurantoin-induced cytotoxicity in Hep G2 cells. As shown in Fig. 1D, compound 4 was found to protect cells from nitrofurantoin with an $\mathrm{EC}_{50}$ of $23.81 \pm 0.5 \mu \mathrm{M}$. This compares with the moderate protective effect of compound $3\left(\mathrm{EC}_{50}=150.9 \pm 6.4 \mu \mathrm{M}\right.$; Fig. 1C). It has been reported that the hepatotoxicity induced by nitrofurantoin is mediated by various events including oxidative stress, ${ }^{15)}$ the inhibition of mitochondrial respiration, ${ }^{16)}$ and the activation of $\mathrm{CD} 8+\mathrm{T}$ cells. ${ }^{17)}(-)$-Epigallocatechin gallate (EGCG), has been reported to inhibit lipid peroxidation in liver mitochondria and microsomes. ${ }^{18)}$ Therefore, we used EGCG as a positive assay control; it was found to have an $\mathrm{EC}_{50}$ of $124.4 \pm 8.6 \mu \mathrm{M}$. This observation also supports the proposed correlation of hepatoprotective effects of compounds $\mathbf{3}$ and $\mathbf{4}$ with their antioxidative effects.

However, further studies are necessary to verify this and to elucidate the mechanistic bases for the hepatoprotective effects exerted by compounds 3 and $\mathbf{4}$.

In summary, a bioassay-guided investigation of the $\mathrm{MeOH}$ extract of Galla Rhois led to the isolation of two phenolic compounds, an equilibrium mixture of 3-galloyl-gallic acid and 4-galloyl-gallic acid isomers (compound $\mathbf{3}$ ), and $1,2,3,4,6$-penta- $O$-galloyl- $\beta$-D-glucopyranose (compound 4), as active principles, and these were found to possess hepatoprotective effects versus tacrine- or nitrofurantoin-induced cytotoxicity in Hep G2 cells. The hepatoprotective effects of compounds $\mathbf{3}$ and $\mathbf{4}$ have not, to the best of our knowledge, 
A)

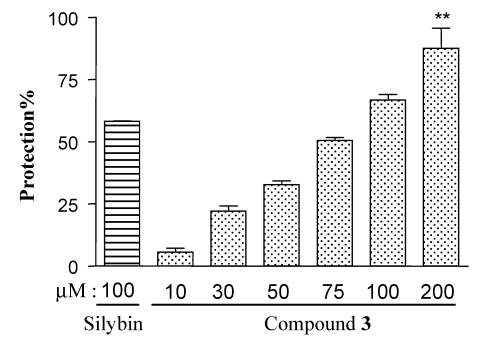

C)

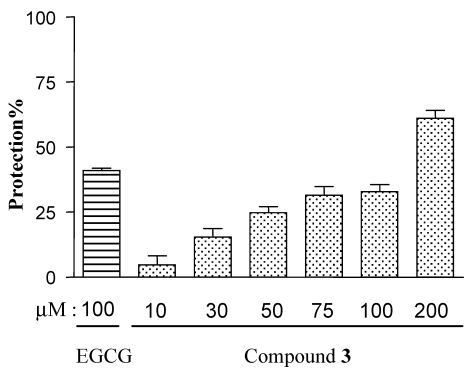

B)

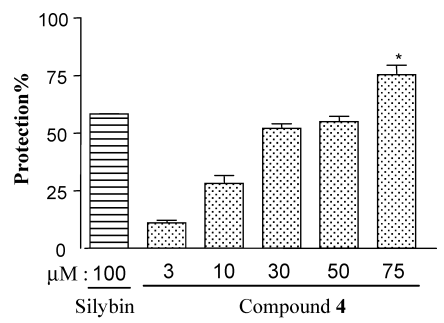

D)

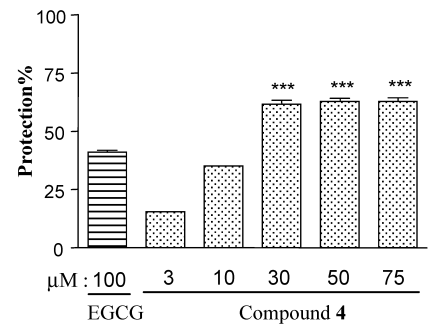

Fig. 1. The Hepatoprotective Effects of Compounds $\mathbf{3}$ and $\mathbf{4}$ on Drug-Induced Cytotoxicity in Hep G2 Cells

Cytotoxicity was assessed after incubating for $2 \mathrm{~h}$ with $1.2 \mathrm{~mm}$ of tacrine (A and B) or $1.7 \mathrm{~mm}$ of nitrofurantoin (C and D) in RPMI medium. The values shown represent the means \pm S.D. of three experiments. Significantly different from the control; $* p<0.05, * * p<0.01, * * * p<0.001$. Silybin or ( - )-epigallocatechin gallate (EGCG) were used as positive controls.

been reported previously, which suggests that these compounds be further evaluated as potential hepatoprotective agents.

Acknowledgements This work was supported by the Korea Research Foundation Grant (KRF-2004-005-E00091).

\section{REFERENCES}

1) Watkins P. B., Zimmermann H. J., Knapp M. J., Gracon S. I., Lewis K. W., J. Am. Med. Assoc., 271, $992-998$ (1994).

2) Edoute Y., Karmon Y., Roguin A., Ben-Ami H., Isr. Med. Assoc. J., 3, $382-383$ (2001).

3) Grant M. H., Duthie S. J., Gray A. G., Burke M. D., Biochem. Pharmacol., 37, 4111-4116 (1988).

4) Cho H., Jun J. Y., Song E. K., Kang K. H., Baek H. Y., Ko Y. S., Kim Y. C., Planta Med., 67, 750-751 (2001).

5) Song E. K., Cho H., Kim J. S., Kim N. Y., An N. H., Kim J. A., Lee S. H., Kim Y. C., Planta Med., 67, 876-877 (2001).

6) Oh H., Kim J. S., Song E. K., Cho H., Kim D. H., Park S. E., Lee H. S., Kim Y. C., Planta Med., 68, 748-749 (2002).

7) Oh H., Ko E. K., Jun J. Y., Oh M. H., Park S. U., Kang K. H., Lee H.
S., Kim Y. C., Planta Med., 68, 932-934 (2002).

8) Tian Y. H., Kim H. C., Cui J. M., Kim Y. C., Arch. Pharm. Res., 28, 44-48 (2005).

9) Zhu Y. P., "Chinese Materia Medica," Harwood Academic Publishers, Amsterdam, 1998, pp. 659-660.

10) Kim H. J., Jang D. I., Choi S. W., J. Food Sci. Nutr., 2, 285-290 (1997).

11) Cha B. C., Lee S. B., Rhim T. J., Lee K. H., Kor. J. Pharmacogn., 31, 185-189 (2000).

12) Nishizawa M., Yamagishi T., Nonaka G., Nishioka I., J. Chem. Soc. Perkin Trans. I, 1982, 2963-2968 (1982).

13) Khanbabaee K., Lotzerich K., Tetrahedron, 53, 10725-10732 (1997).

14) Galisteo M., Rissel M., Sergent O., Chevanne M., Cillard J., Guillouzo A., Lagadic-Gossmann D., J. Pharmacol. Exp. Ther, 294, 160-167 (2000).

15) Carbonera D., Angrilli A., Azzone G. F., Biochim. Biophys. Acta, 936, 139-147 (1988).

16) Lim L. O., Bortell R., Neims A. H., Toxicol. Appl. Pharmacol., 84, 493-499 (1986).

17) Kelly B. D., Heneghan M. A., Bennani F., Connolly C. E., O’Gorman T. A., Am. J. Gastroenterol., 93, 819-821 (1998).

18) Okuda T., Kimura Y., Yoshida T., Hatano T., Okuda H., Arichi S., Chem. Pharm. Bull., 31, 1625-1631 (1983). 